\title{
Sociologia em duplo-hélice: entre conhecer e actuar em contexto de políticas públicas Iniciativa Bairros Críticos - Operação Vale da Amoreira
}

\author{
João Afonso * \\ Bernardo Soares Coelho ${ }^{* *}$
}

\begin{abstract}
$\mathrm{R}$ mo: Conhecimento e acção são muitas vezes vistos como pertencentes a domínios distintos e que não se entrecruzam: por um lado, o cognitivo; por outro o da intervenção na realidade. Quando imaginamos a prática sociológica em processos de formulação de políticas públicas não deixa de emergir uma tensão originária dessa distinção quase primordial. Tendo como referente empírico a experiência na Iniciativa Bairros Críticos, aquilo que se propõe é um percurso reflexivo sobre a prática sociológica em contexto de políticas públicas, tentando desvendar os processos que marcam esta relação entre conhecimento e acção. Neste desvendamento propomos uma sociologia em duplo-hélice que articula conhecimento sociológico e acção política e onde se conjuga a prática de uma sociologia sensível e objectivos do planeamento estratégico.
\end{abstract}

Palavras-chave: Políticas Públicas; Participação; Parcerias; Planeamento Estratégico; Sociologia em duplo-hélice.

\section{Introdução}

Aquilo que se propõe neste artigo é partilhar com o leitor um percurso reflexivo sobre a prática sociológica em contexto de políticas públicas, tentando desvendar os processos que marcam a relação entre conhecimento e acção. Neste processo, tomamos como referente empírico a experiência em contexto da Iniciativa Bairros Críticos ${ }^{1}$, nomeadamente a elaboração de um "plano de acção" para a Freguesia do Vale da Amoreira, Concelho da Moita. O objectivo principal desta iniciativa, coordenada pelo Instituto Nacional de Habitação², era a definição de um Programa de Intervenção Urbana, inovador em termos de procedimentos, implementação e avaliação, dando relevo à coordenação estratégica e à convergência de acções entre os vários actores envolvidos ${ }^{3}$, possibilitando uma acção integrada e globalizante para o território, com carácter de projecto-piloto passível de aplicabilidade noutras zonas ou bairros com características idênticas. O maior desafio da iniciativa, e daí também o seu carácter inovador, seria a estruturação de um sistema de parceria eficaz, dinâmico e alargado de co-decisão a implementar ao longo do processo de construção do projecto de intervenção, fugindo a uma matriz de participação pública meramente opinativa. Este desafio abriu a possibilidade de, em parceria com um vasto leque de actores locais, construir-se um projecto inovador, capaz de romper com as anteriores lógicas de planeamento urbano, baseadas em conteúdos demasiado físicos e em formas de gestão demasiado burocratizadas. Esta postura

\footnotetext{
* Sociólogo, Técnico da CCIJRLVT. Contacto: joao.afonso@ecdr-lvt.pt

** Sociólogo e investigador. Contacto: bernardo.coelho@iscte.pt

1 A Iniciativa Bairros Críticos foi dirigida a três bairros das áreas metropolitanas do território nacional, a saber: Bairro do Lagarteiro, Concelho do Porto, Área Metropolitana do Porto; Bairro da Cova da Moura, Concelho da Amadora, Área Metropolitana de Lisboa (margem norte); e Bairro do Vale da Amoreira, Concelho da Moita, Área Metropolitana de Lisboa (margem sul).

2 Organismo público coordenador da iniciativa a nível nacional.

3 A proposta da iniciativa dava um especial destaque à participação cívica, que deveria ser central em todo o processo e condiçāo para o êxito da intervençāo, evitando a lógica de anteriores programas que funcionaram num esquema sectorial decidido longe do lugar da intervençāo e dos seus actores. Iesta forma, identificam-se os seguintes actores envolvidos no processo: actores locais colectivos (associaçōes, IPSS, ONG's); representantes de serviços descentralizados do Estado e representantes ministeriais; poder autárquico (Câmara Municipal da Moita, Junta de Freguesia do Vale da Amoreira).
} 
de abertura à realidade local e ao conhecimento que aí se enraíza marca o desenvolvimento das diferentes etapas: da construção participada do diagnóstico à definição de um plano de intervenção local; passando pela montagem e definição de modelos de gestão da operação e das parcerias; bem como pela estruturação de um sistema de acompanhamento e de monitorização do processo de intervenção.

Neste sentido, o nosso objectivo foi elaborar um projecto com base num processo de planeamento estratégico que reconhecesse os valores do território em causa, mantendo-os e promovendo-os de forma cumulativa e sinérgica, intervindo de forma relacional, promovendo os vínculos entre o território, as actividades e as pessoas. Ou seja, criando pontes entre a tradição, sedimentada em quadros relacionais específicos e em formas particulares de saber-fazer, e a mudança (Silva, 2006). A Operação Vale da Amoreira ${ }^{4}$ integra várias dimensões de intervenção urbana, integra funções, integra parceiros, integra recursos e acima de tudo integra a população e os seus saberes, tornando-a numa iniciativa sustentável, contribuindo para um efectivo desenvolvimento do território, atenuando a exclusão social e levando a uma melhoria das condições de vida da população.

Este artigo é um exercício auto-reflexivo da experiência no terreno, de uma actividade sociológica sobre "a sociologia praticada". Um pensamento sobre a relação com o terreno e com os sujeitos que o tornam num espaço vivido e recheado de experiências e expectativas. Trata-se de um exercício reflexivo sobre as relações sociais que se estabelecem num processo desta natureza.

Identificam-se três nós de problematização sociológica sobre a prática da sociologia no contexto de políticas públicas: em primeiro lugar, aquele em que se tenta compreender o contributo da sociologia como uma forma de conhecimento, implicando uma postura que não se afasta de um processo de pesquisa (entre conhecer e actuar no Vale da Amoreira transformado em objecto, posto e recomposto). $\mathrm{O}$ segundo ponto de problematização situa-se em torno das implicações metodológicas e dos fundamentos epistemológicos que são exigidos por uma postura que resgate os sujeitos para o centro dos processos de planeamento (o tempo e o espaço bem como o movimento como cenários metodológicos). Finalmente, reflecte-se sobre a importância de pensar - e desocultar - os quadros relacionais que se estabelecem num processo desta natureza.

\section{Entre conhecer e actuar}

Conhecimento e acção são muitas vezes vistos como pertencentes a domínios distintos e mutuamente exclusivos: por um lado, o cognitivo e, por outro, o instrumental ou a intervenção na realidade. Quando imaginamos a prática sociológica numa relação com os processos de formulação de políticas públicas, não deixa de emergir uma tensão originária daquela distinção quase primordial. Uma tensão que tem na relação mais ou menos conflituosa entre ciência e estado, ou de outra forma, entre conhecimento e apropriação instrumental e operatória do saber, a sua razão latente. Esta dimensão conflitual é transportada para o interior da prática sociológica, ganhando materialidade, simultaneamente, num questionamento e numa prática.

$\mathrm{O}$ questionamento relaciona-se com o modo como o sociólogo, engajado nestes processos de formulação de políticas públicas, estabelece a relação entre conhecimento e acção social salvaguardando a sua autonomia. A prática surge como consequência da indagação anterior e define-se pela vigilância epistemológica e metodológica da actividade sociológica neste contexto.

O envolvimento em processos de formulação de políticas, em particular, se estas forem políticas públicas conduzidas e organizadas no quadro do Estado, inscreve as contribuições da sociologia e do sociólogo em processos políticos formais (Silva, 2006). A sua presença não deixa de ser uma forma de informação, monitorização e de legitimação de tais processos. Levanta-se então uma série de problemas específicos que se podem organizar numa constelação interrogativa cujo centro gravitacional se encontra na prática sociológica de fronteira - aquela que se situa entre a cientificidade e a tecnicidade do conhecimento. São questões que derivam do problema da relação entre a ciência e a

\footnotetext{
${ }^{4}$ Para melhor se conhecer o projecto desenhado, percebendo as suas dimensões de intervenção e projectos estruturantes para a mudança, ver "Iniciativa Bairros Críticos - Operação Vale da Amoreira", 2006. Para consulta no Centro de Estudos Territoriais do ISCTE.
} 
política ou da autonomia da primeira em relação à segunda. Este estatuto liminar não é apenas fruto de uma racionalização da experiência sociológica passada, ele é sentido no decurso quotidiano da prática sociológica.

É na contemporaneidade que a prática da sociologia ganha corpo, obrigando a um esforço de constante vigilância reflexiva que se pode traduzir sinteticamente em duas questões: em que moldes se estabelece essa relação entre conhecimento sociológico e acção social traduzida em acção política? E, neste contexto específico, quais os contributos da sociologia e do sociólogo nestes processos de acção/intervenção pública?

De uma maneira simples podemos dizer que, como todas as ciências, a sociologia contribui para a acção social com o conhecimento (Silva, 2006). $\mathrm{O}$ trabalho sociológico é eminentemente a produção de conhecimento sendo, no entanto, uma forma de conhecimento singular sobre as relações que produzem e transformam as estruturas sociais. Este conhecimento traduz-se em competências e capacidades, de assimilar, interpretar, produzir e comunicar informação baseado numa atitude de descoberta e de desvendamento, e é portador e produtor de recursos cuja mobilização não se limita ao trabalho de pesquisa, mas pode formatar estratégias de acção (Silva, 2006). Isto é, a sociologia é portadora de estratégias de produção da realidade, significando que as dimensões cognitivas e instrumentais não são mutuamente exclusivas na prática sociológica, tornando-se possível conceber uma prática sociológica de articulação.

Nesta sociologia de articulação inscreve-se uma possibilidade de resolução do problema da autonomia entre ciência e acção política, na medida em que a contribuição da sociologia radica precisamente naquilo que teme perder, isto é, no seu estatuto de autonomia enquanto saber e campo científico e profissional (na sua forma de conhecimento específico). Para se estabelecer uma relação produtiva entre a sociologia e as prioridades da agenda política, pressupõe-se que o sociólogo dispõe do tempo e dos instrumentos necessários para problematizar as questões sociais, redefinindo-as e percebendo de forma provisória as dinâmicas que aí se inscrevem. Ao participar em processos de formulação de políticas públicas no quadro do Estado, o sociólogo não fica subitamente desprovido de capacidade de análise crítica e de problematização dos processos e dinâmicas que observa. Pelo contrário, trabalhar nestes cenários implica o aguçar da reflexividade, isto é, exige a atenção redobrada na análise dos processos e dinâmicas em que está envolvido. O sociólogo transporta desta forma para o campo da intervenção e do planeamento de políticas a capacidade prática de interpelação: interrogando, questionando, problematizando, transformando as visões estáticas em visões dinâmicas sobre as dinâmicas sociais. No fundo, o conhecimento produzido traz profundidade ao olhar sobre o real.

Não se trata do exagero da importância da sociologia enquanto forma de conhecimento, nem da declaração de uma pretensa superioridade ontológica do conhecimento e das interpretações assim produzidas, mas apenas de perceber o planeamento como um processo de pesquisa. Pode parecer paradoxal afirmar tal primado quando o tema é a abertura da sociologia ao exterior, e a mobilização dos seus recursos para a acção, pois, o primado da investigação significa a precedência do desenvolvimento interno da sociologia enquanto disciplina científica. Mas, a verdade é que a contribuição da presença do sociólogo seria estéril caso a base essencial do seu trabalho e pensamento tivesse sido perdida ou secundarizada (Silva, 2006).

Pensar o planeamento afastado das lógicas de produção e de expressão de conhecimento, ou não conceber o planeamento como um processo de construção de conhecimento é insistir na ocultação. O obscurantismo transforma o planeamento em algo simplesmente tecnocrático e normativo onde aquilo que fica escondido é no fundo o que se deve procurar desvendar trazendo para a luz as dinâmicas que constituem a realidade objecto de intervenção.

Neste sentido, o planeamento pressupõe um acto de pesquisa e de produção de conhecimento, de produção e reinvenção da realidade podendo ser entendido como uma forma de desenvolvimento do conhecimento em estreita relação com a materialidade do mundo social que possibilita novas e inovadoras formas de acção, criadas na conjugação das motivações internas das esferas do Estado, através de políticas públicas e da assimilação e tradução em novas formas de mobilização social e a acção de actores colectivos mais ou menos formalizados. 
Esta posição exige não afastar destes processos a dimensão fundamental da construção teórica que é uma construção baseada numa dialéctica, num vai-e-vem constante, entre os fenómenos estudados e a sua materialidade objectiva e os conhecimentos acumulados, promovendo um questionamento e enriquecimento biunívoco. Abdicar da construção e reflexão teórica em processos de formulação de políticas públicas, pode significar a remissão dos contributos da sociologia para a esfera da tecnicidade pura, promovendo a passagem da sociologia para o campo da tecnocracia.

Se o processo de planeamento é na sua essência a construção de conhecimento sobre um real a intervir e se o conhecimento produzido segue duas trilhas, uma de internalização no campo do conhecimento sociológico numa lógica de cumulatividade, e outra de externalização promovendo a acção criticamente fundamentada, o esforço reflexivo deve centrar-se nas condições e formas de constituição desse conhecimento singular sobre o território do Vale da Amoreira, percebendo como o trabalho sociológico se afirma como um espaço de confluência entre conhecimento e acção.

\section{Vale da Amoreira como objecto: do posto ao recomposto}

De uma forma simples e sintética podemos dizer que o objecto é o Vale da Amoreira enquanto território social e urbano apresentado pelo discurso político como um território crítico. Mas, numa intervenção sociologicamente atenta, o primeiro esforço deve ser a desconstrução desse objecto porque há certamente uma distinção entre aquilo que são os problemas sociais incorporados pela agenda política e a definição de um problema sociológico.

Esta divergência torna-se evidente se pensarmos que apesar de nos confrontarmos com um objecto delimitado à partida, ele tem uma abrangência quase infinita do ponto de vista da problematização e da interrogação sociológica. $\mathrm{O}$ que nos é dado à partida é essencialmente um objecto de intervenção política definido de acordo com objectivos políticos. Aquele que é o ponto de partida para a construção de uma acção política, motivando a convocação da sociologia enquanto saber especializado, será para os sociólogos apenas o seu ponto de chegada: a constituição de um objecto de intervenção e de um plano de intervenção sedimentado num conhecimento profundo sobre o Vale da Amoreira não só analitica e teoricamente fundamentado como também enraízado na realidade dinâmica deste território.

Na sombra da diferença básica entre o objecto político e o objecto de estudo para a sociologia está aquilo que podemos designar como a visibilidade social do Vale da Amoreira. É uma visibilidade que se apoia nos discursos mediáticos, académicos e nos discursos correntes do saber quotidiano, conferindo ao Vale da Amoreira uma imagem externamente produzida: território de marginalidade, porque afastado de diferentes centros (político, económico, urbano e cultural). Tomar como objecto estes discursos, percebendo de que forma são internamente percebidos e reproduzidos (ganhando sentidos práticos), é uma forma de evitar ser "apanhado" no objecto, de transportar tudo o que torna possível a experiência dóxica do mundo social. Isto é, trata-se de interrogar não só a construção preconcebida deste mundo mas também os esquemas cognitivos que estão na origem da construção desta imagem.

O discurso político transforma a imagem em objecto mutante. Enquanto autor do objecto, o poder político confere uma legitimidade especial no acesso ao Vale da Amoreira podendo ser considerado o primeiro dos porteiros simbólicos deste terrritório. Na verdade, não nos limitamos a receber um objecto de estudo predefinido, com ele recebemos também um conjunto de interlocutores privilegiados ${ }^{5}$, previamente seleccionados e mobilizados, com quem devemos encetar uma lógica participativa de construção de conhecimento sobre o Vale da Amoreira, concebendo as bases para uma intervenção futura. Aqui enreda-se o perigo de confusão entre interlocutores privilegiados e o objecto de estudo. De facto, dá-se uma sobreposição parcial entre estes actores colectivos locais e o objecto de estudo, na medida em que fazem parte da paisagem institucional do Vale da Amoreira, aí intervêm, construindo uma realidade da qual

\footnotetext{
Designado no seio da Iniciativa Bairros Críticos como Grupo de Parceiros Locais. Deste grupo fazem parte: actores colectivos locais ou de incidência local (IPSS, ONG's, etc); representantes dos diferentes Ministérios que fazem parte da Iniciativa Bairros Críticos; representantes de serviços descentralizados do Estado; poder autárquico (Câmara Municipal da Moita e Junta de Freguesia do Vale da Amoreira).
} 
também fazem parte. Mas, o Vale da Amoreira não se esgota nestes actores.

O carácter processual da construção de objecto de estudo, ou melhor da sua desconstrução e recomposição, coincide com a fase de arranque do trabalho de planeamento e com o início do trabalho de terreno. Espécie de condensação metodológica, que toma como objecto o trabalho social de construção do objecto pré-construído (Bourdieu, 2001: 28), permitindo a resolução dos problemas que temos vindo a enunciar: (i) a distinção entre objecto político e objecto sociológico; (ii) o excesso de visibilidade do Vale da Amoreira e da sua produção social e, finalmente, (iii) a sobreposição entre objecto e interlocutores.

Num território marcado por uma história já longa de intervenções, o trabalho colectivo necessário para dar a conhecer e fazer reconhecer o Vale da Amoreira e os seus problemas como legítimos sedimenta-se, em grande parte, em diagnósticos, planos de actividades e projectos de intervenção, bem como na história e nos capitais de experiência acumulados pelas diferentes instituições no terreno. Desta forma, tornou-se inevitável a recolha da informação disponível sobre o Vale da Amoreira, bem como a elaboração e o preenchimento das fichas de caracterização dos parceiros locais com informação específica sobre cada instituição. Da análise desta informação resulta um desenho mais definido do objecto de estudo em que se transforma o Vale da Amoreira: a informação permite o retracto sociográfico do território e a delimitação das principias dinâmicas e estruturas de organização do Vale da Amoreira enquanto mundo social.

Tendo em consideração que num processo de planeamento em sociologia o objecto de estudo e o de intervenção tendem a coincidir, podemos dizer que este processo de problematização e recomposição do Vale da Amoreira enquanto objecto durou toda a fase de diagnóstico. Num primeiro momento, tratou-se da sua transformação em objecto de estudo (identificando as dinâmicas e estruturas sociais que importava analisar em maior detalhe); numa segunda fase, este esforço de recomposição centra-se na passagem do objecto de estudo para o objecto de intervenção. Um objecto de intervenção que surge fundamentado num conhecimento enraízado e teoricamente discutido, abandonando o carácter de enunciado da agenda política. Nele estão definidas as dimensões fundamentais por onde pode passar a mudança e o desenvolvimento participativo e sutentado do Vale da Amoreira.

\section{O Resgate do Sujeito}

No caso das ciências sociais e da sociologia em particular, a relação entre conhecimento e acção, ou entre conhecimento e intervenção pública, é particularmente densa e complexa. Não só devido à vigilância que a sociologia exerce sobre si mesma, mas também porque aquela relação é marcada por uma ausência sempre presente: os sujeitos.

Os sujeitos estão no centro desta densificação e complexificação por duas razões essenciais. Em primeiro lugar, porque a sociologia estuda processos e dinâmicas de constituição e mudança de estruturas sociais. $\mathrm{O}$ conhecimento que oferece para a construção de políticas públicas não é só sobre os sujeitos sociais, e as formas como estes se inscrevem em quadros mais gerais de condições objectivas, como é um conhecimento com eles produzido e que deles depende.

É esta preocupação em resgatar os sujeitos e as suas experiências ao universo das ausências, recusando tratá-los enquanto meros alvos de intervenções futuras, que dá um carácter único e singular à contribuição da sociologia nestes contextos de acção sobre a realidade. Em segundo lugar, na Iniciativa Bairros Críticos esta relação ganha novos contornos com a emergência de um termo que se tem tornado omnipresente nos discursos políticos, científicos e nos discursos correntes do quotidiano quando se fala de planeamento e formulação de políticas públicas: participação.

Se, por um lado, podemos perceber a emergência das metodologias participativas como a legitimação da preocupação da sociologia com os sujeitos, objectos ou alvos finais das políticas que ajuda a desenhar, dando-lhes um novo poder e protagonismo (marcando a passagem de objecto para sujeito); por outro, este termo não é suficientemente claro quer do ponto de vista do seu significado quer do ponto de vista das suas implicações. Muitas vezes faz-se uma utilização apriorística e reificada, como se tivesse um significado evidente ou como se a expressão fosse auto-explicativa. É, por isso, necessário partir de 
uma posição distinta percebendo que este termo incorpora uma profunda ambiguidade e nele se sedimentam significados múltiplos. Nem sempre sabendo muito bem do que estão a falar, e nem sempre estando a falar exactamente da mesma coisa, os processos participativos tornaram-se para os discursos correntes do quotidiano numa nova forma de reivindicação cidadã. Para o poder político, a "participação" transforma-se numa forma de consolidação e legitimação das suas opções e para as ciências sociais, e para a sociologia em particular, transforma-se num duplo campo de actividade e de problematização (teoria e prática), afirmando-se como espaço de indagação teórico-conceptual e como nova janela para a prática profissional.

De forma genérica, e afastando as euforias que cercam muitas vezes a utilização deste termo, podemos imaginar que o planeamento participativo de políticas públicas passa por três pontos fundamentais:

Em primeiro lugar, é necessário colocar no centro a combinação entre necessidades, representações, projectos e recursos sociais (Silva, 2006). Baseia-se na recusa da identificação isolada das necessidades e problemas de uma forma que as afaste para o pólo oposto da identificação dos recursos e das oportunidades. Deve sim promover a ligação entre as situações sociais, olhadas criticamente a partir do exterior (o olhar do sociólogo) e as percepções e as estratégias de gestão e organização da experiência quotidiana pelas pessoas que as vivem.

Em segundo lugar, é a afirmação do planeamento das políticas como um processo social (Guerra, 2000). Esta dimensão de processo social é fundamental para a criação de uma relação com os actores locais, atribuindo-lhes um lugar central neste percurso de construção de conhecimento e de criação de futuro. Os actores são pessoas que partilham modos de existência que não estão fora, mas sim dentro dos problemas e são os detentores de recursos do seu desenvolvimento (Silva, 2006). As pessoas são vistas como recursos, como os principais recursos do seu próprio desenvolvimento e a aposta centra-se na sua capacitação e ampliação dos poderes para agir (empowerment).

Em terceiro lugar, as estratégias de natureza participativa inscrevem-se numa lógica relacional entre tradição e mudança. Por um lado, é inegável a vocação transformadora da participação criando realidade, convertendo problemas em oportunidades materializando recursos, lançando iniciativas para impulsionar progressos objectivos e mudar as formas de acção e de organização. Por outro lado, preocupa-se em estabelecer pontes de diálogo entre os padrões de cultura enraizados e incorporados numa memória colectiva feita prática, e a iniciativa de criação de futuro (Silva, 2006).

\section{Sociologia em duplo-hélice: tempo, espaço e movimento}

O envolvimento num processo de planeamento de intervenção com base territorial, obriga a pensar duas variáveis que desde sempre têm sido fontes de problematização na sociologia: o tempo e o espaço. Pensemos, com Leibniz, que o espaço é a ordem possível da coexistência dos fenómenos, sendo que a ordem é geralmente o modo como os fenómenos são percepcionados.

O espaço é a ordem ou o modo de percepcionar os objectos, mas não tem significado sem eles (Pearson, 2004 [1892]). Tal como o mundo social - e a existência individual -, a realidade existe na exacta medida em que a percepcionamos e somos capazes de traduzir, gerir e incorporar as experiências. Existe uma dimensão subjectiva na construção do espaço que se traduz naquilo que cada um é capaz de traduzir das suas experiências quotidianas, tornando-as em formas de enriquecimento e de construção de si na relação com o mundo. Assim, o espaço não é apenas físico, é social e socialmente percebido, vivido e construído.

Se o espaço é um modo que a faculdade de percepção encontra para distinguir objectos e para os organizar, dando-lhes sentido, construindo o real, o tempo é um segundo modo. Da mesma forma que o espaço marca a coexistência das percepções numa época do tempo, o tempo marca a progressão das percepções numa posição do espaço. A combinação destes dois modos é o movimento, que é o modo fundamental como os fenómenos nos são apresentados (Pearson, 2004 [1892]).

Pedindo emprestada à biologia a metáfora do duplo hélice, podemos imaginar que neste processo de pesquisa e de formulação de políticas públicas nos encontramos num turbilhão que se forma em torno de dois movimentos de sentidos opostos e duas temporalidades distintas: um movimento centrí- 
peto, um movimento centrífugo; uma temporalidade sagrada e outra profana (Hall, 1989). A coexistência entre tempos e movimentos é complexa, provocando a sensação de turbilhão. Este é um processo de planeamento que não se afasta dessa imprevisibilidade, nem a tenta resolver ou neutralizar, pelo contrário, nela percebe a força e a dinâmica desse território a intervencionar ${ }^{6}$. De facto, sem entrar e desvendar os meandros dessa imprevisibilidade (realidade), ou pelo menos desocultar as formas como ela se dá a conhecer na contemporaneidade da pesquisa, nada de mobilizador para a mudança pode ser pensado. Trata-se de entender o mundo social que constitui o Vale da Amoreira para lá das evidências, desvendando as dimensões ocultas dessa realidade, isto é, os processos e mecanismos que a constituem (Danermark et al., 2002).

$\mathrm{O}$ primeiro movimento, que podemos denominar de centrípeto representa um mergulho sobre a realidade do Vale da Amoreira e um centramento nas suas particularidades. Constitui-se na relação de pesquisa e trabalho participativo desenvolvido com os actores locais e nele se sedimentam as tentativas de desocultação sobre a realidade do Vale da Amoreira, ganhando forma um campo de confluência e negociação entre diferentes formas de saber (Davies, 2005; Moscovici e Willem, 1991; Santos, 2000, 2003, 2006). O movimento centrípeto guia-se por uma lógica de abertura sobre o que cada um tinha como retrato da realidade do Vale da Amoreira, possibilitando a construção do Vale da Amoreira como espaço pessoal marcado e definido de acordo com as experiências sociais de cada um dos actores envolvidos. Este é um movimento de desocultação através do qual o Vale da Amoreira abandona a zona sombria criada pelo excesso de visibilidade social marginalizante de que sofre, permitindo revelar a diversidade e a multiplicidade das representações e práticas sociais que o compõem.
Podemos enquadrar este movimento constitutivo de uma postura metodológica no âmbito de uma sociologia das ausências (Santos, 2003, 2006), na medida em que o objectivo desta sociologia é revelar a diversidade e a multiplicidade das práticas sociais. É uma sociologia que assume a realidade como independente do conhecimento que dela temos à partida, esta realidade não está completamente acessível à observação imediata. A realidade não é transparente, os mecanismos, processos e dinâmicas estruturantes encontram-se numa dimensão profunda da realidade que não se observa como simples evidência, mas marcam e fazem acontecer o mundo social do Vale da Amoreira (Danermark et al., 2002)

Com base na intervenção territorializada e com um objecto delimitado à partida, importa perceber que espaço é este que se chama Vale da Amoreira? O que lhe dá forma? Que dinâmicas e actores o constituem?

De facto, trata-se da indagação e interpretação das percepções dos actores locais sobre o espaço que produzem todos os dias. Interroga-se a forma como conciliam e traduzem essas percepções sobre o real do Vale da Amoreira, como fazem coexistir experiências diversas no seu tempo quotidiano, como moldam o território àquilo que são os seus sentimentos, sensações e emoções. Estando, em grande parte, a constituição do Vale da Amoreira dependente desta dimensão subjectiva sempre oculta (mas de efeitos objectivos), é necessário activar uma sociologia sensível, uma sociologia atenta aos pequenos indícios (Maffesoli, 1998; Pais, 2002). Adoptar uma prática sociológica que permita desvendar e desocultar as percepções formatadoras desta realidade é complexo, pois trata-se de uma realidade densa e múltipla

\footnotetext{
${ }^{6}$ Acompanhando a imprevisibilidade das dinâmicas do processo de planeamento participativo, emergem duas grandes forças constitutivas da identidade do Vale da Amoreira enquanto processo de produção de si como território vivido: (i) fragmentação; (ii) auto-centramento. A fragmentação intensifica a pluralidade, percebendo-se o Vale da Amoreira como uma multiplicidade de formas de existência e de vivência e experimentação. Surge como espaço possibilitador de pontos de fuga em relação aos discursos e imagem extremamente produzida: marginalidade, porque afastado de diferentes centros (político, económico, urbano e cultural). Ao mesmo tempo esta força de fragmentação espartilha o território a diferentes níveis: espaço urbano; coesão e inserção social; governabilidade; trajectórias escolares e profissionais. Contrariando esta força fragementadora, encontramos concomitantemente um movimento de fechamento que corresponde a uma força de autocentramento. Uma tentativa de criação de sentido de unidade, de uma imagem, de um referente comum. É a afirmação de uma espécie de mitologia, uma crença na existência de uma identidade própria e única que une toda a malha social e urbana da freguesia do Vale da Amoreira. Mas este movimento resulta num processo de enredamento do Vale da Amoreira sobre si mesmo; um centramento dos agentes sociais no espaço delimitado da freguesia; um centramento das expectativas de existência de acordo com uma realidade territorial e simbólica em busca de valorização mas de reconhecimento sempre adiado.
} 


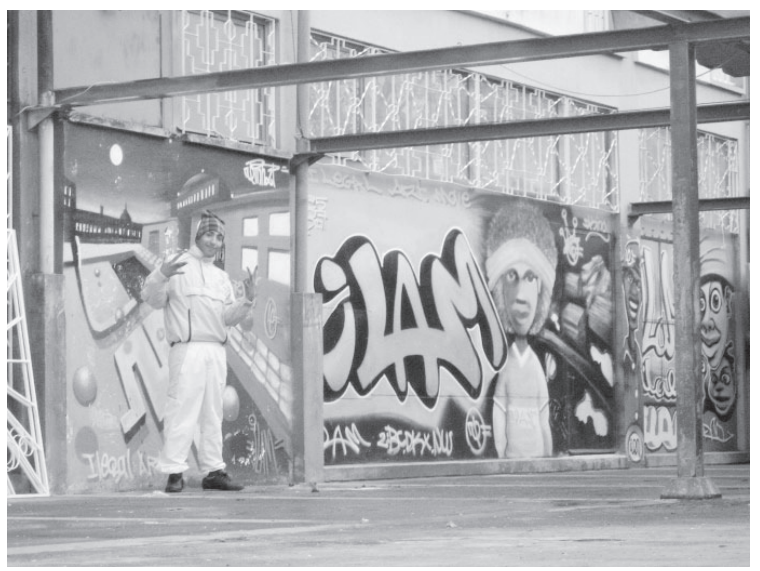

Grafittis - Vale da Amoreira

Precisamos de uma aproximação às estratégias etnográficas. Uma postura generativa próxima daquela concebida por Glaser e Strauss (1967), conhecimento que emerge enraizado da própria realidade e de acordo com os ritmos de explicitação e interpretação dos fenómenos emergidos. Uma postura generativa não pode ser simplesmente pensar a realidade como um processo dinâmico, não se limita a perceber a realidade de bairros em crise dessa forma, deve existir uma postura perante os sujeitos e o terreno que permita o estabelecimento da confiança básica entre os pesquisadores e os interlocutores locais ao ponto dos fenómenos se desocultarem no quadro das relações estabelecidas (Davies, 2005; Moscovici e Willem, 1991).

O segundo movimento, designado centrífugo, é contemporâneo ao acto de produção do trabalho colectivo de planeamento da acção e corresponde à natureza do produzido. Este segundo movimento, revela-se na imaginação da realidade futura. É uma espécie de intersecção entre a realidade vivida (com racionalizações várias) e aquela outra realidade imaginada ou sonhada para o futuro. É através deste movimento que se passa de uma lógica de desvendamento para uma lógica de constituição de futuro, de formulação da acção transformadora, da investigação das alternativas que cabem no horizonte das possibilidades concretas, transformando o sonho em projecto de existência. Passagem do desvendamento salvaguardado por uma sociologia das ausências para a prática de uma sociologia das emergências (Santos, 2003, 2006). Forma de ampliação do presente, juntando ao real amplo as possibilidades e expectativas futuras que ele comporta (Santos, 2003, 2006), trata-se de fazer passar os desejos de futuro da dimensão onírica para uma dimensão racionalizada, isto é, transformar o sonho em projecto de existência. Tal ampliação simbólica é uma forma de imaginação sociológica que visa um duplo objectivo: conhecer melhor as condições de possibilidade da esperança; definir princípios de acção que promovam a realização dessas condições (Santos, 2003). É este movimento que nos leva até ao ponto de chegada num processo de formulação de políticas públicas: o plano de acção.

O desafio metodológico situa-se, precisamente, na confluência entre estes dois movimentos (centrípeto e centrífugo), na articulação entre uma sociologia sensível, em grande medida apoiada em estratégias metodológicas de cariz etnográfico, e os métodos, técnicas e objectivos do planeamento (bem como, o objectivo político que nos abriu portas ao desenvolvimento deste trabalho: a formulação de um plano de intervenção para o Vale da Amoreira). A plasticidade metodológica implícita a esta articulação encontra dois importantes alicerces, um de cariz teórico-conceptual e outro de cariz político institucional. O primeiro constitui-se pela emergência de novas formas alternativas de planeamento, promotoras de uma nova centralidade para os sujeitos nos processos e dinâmicas implicados e estabelece uma rede de suporte teórico-conceptual às opções tomadas no desenrolar do processo de planeamento. $\mathrm{O}$ segundo confere um equadramento político e jurídico a um trabalho inovador. Neste ponto, percebe-se com maior clareza o papel de porteiro que o Estado desenvolve num processo desta natureza, conferindo legitimidade aos processos de trabalho livremente desenvolvidos e limitando resistências a estas técnicas.

O processo de globalização tem vindo a impor uma visão mais descentralizada da governação e da administração dos territórios, revelando as dificuldades da administração central em resolver os problemas a nível local, em especial devido às especificidades de cada território. $\mathrm{O}$ crescimento muitas vezes insustentável dos territórios e dos problemas a ele associados têm provocado impactos sobre os paradigmas político-institucionais e nas estruturas que gerem os territórios. Estas novas dinâmicas têm obrigado à tomada de novas atitudes e de uma nova cultura de gestão, como reconhecem Jordi e Castells (1997: 31), "nestas condições, os governos locais e regionais estão a emergir, em todo o mundo, como entidades mais flexíveis, ligadas ao 
terreno das suas identidades, potencialmente capazes de negociar uma adaptação continua à geometria variável dos fluxos do poder". Em Portugal não se assiste ainda a uma verdadeira gestão dos territórios de forma descentralizada e participada, enquanto expressão de um verdadeiro exercício de cidadania, com base na organização e distribuição de responsabilidades e poderes. A conduta de tendência centralista do poder político bem como a diminuta participação cívica das populações continua a estar muito enraizada na cultura portuguesa, criando fortes entraves ao desenvolvimento local. Nos últimos anos, a maioria dos planos elaborados em território português foram pouco, ou nada, participativos; foram dados a conhecer à população, e até aos agentes, na sua fase final, impossibilitando uma verdadeira participação na sua elaboração, negociação e execução. Repare-se que a discussão pública é claramente diferente de formulação participativa de políticas públicas mas têm sido muitas vezes tratados como sinónimos.

O modelo interaccionista do planeamento estratégico surge hoje como aquele que melhor pode dar resposta às necessidades de planeamento territorial na sociedade actual. Tendo por base os pressupostos do modelo clássico, mas ele vai mais além, ao reconhecer o papel fundamental que os actores públicos e sociais devem ter ao longo de todo o processo dadas as suas representações sobre a realidade em que é necessário intervir (Guerra, 2001). Esta é uma das virtudes desta metodologia, a forma como pragmatiza a realidade, estabelecendo as diferenças entre o que se deseja fazer e o que é possível fazer, tendo como objectivo final promover a mudança e gerar novas dinâmicas sociais de uma forma sustentada, estabelecendo uma hierarquia de prioridades de acção de acordo com aquilo que é estruturante para o território.

Em termos metodológicos, o processo de planeamento estratégico tem início no levantamento de todos os actores implicados ou que possam vir a estar implicados, no reconhecimento consensual da necessidade de mudança, seguindo-se na elaboração de um diagnóstico, na definição de uma visão de futuro com suporte num plano de acção detalhado e estruturante, e por fim no desenho de um modelo de gestão que permita a sua execução, monitorização e avaliação. O Planeamento Estratégico, processo do qual resulta posteriormente um Plano com uma visão a prazo para um território específico, deve ser um instrumento de participação e mobilização para o desenvolvimento local e para a melhoria da qualidade de vida da população, assim, deve fomentar os processos de participação desde o seu início. A sua implementação deve ter por base uma activa participação das populações e dos agentes locais, de forma a ser possível interpretar e confrontar as aspirações, capacidades e os próprios interesses dessas comunidades.

A iniciativa Bairros Críticos parece dar este salto, ao romper com as formas e os processos tradicionais de planeamento, propondo um "projecto de bairro"7 desenhado desde baixo pelos actores locais e a população, e envolvendo várias estruturas político/administrativas (Junta de Freguesia, Câmara Municipal e organismos públicos de vários Ministérios) através do diálogo e do trabalho interdisciplinar. De acordo com a resolução do Concelho de Ministros ${ }^{8}$ que aprova a iniciativa, é referido que "as operações a desenvolver pretendem estimular e testar soluções institucionais, procedimentais e tecnológicas inovadoras em termos da concepção, implementação e avaliação da acção pública em áreas urbanas críticas (...)", recorrendo a uma "metodologia, dando forte relevo à coordenação estratégica e à convergência de acção entre diversos actores e assumindo claramente a participação cívica como condição de êxito da intervenção (...)", definindo que a mesma deve ter por base um “(...) grupo de trabalho para, num processo fortemente participado e articulado com as organizações locais, preparar o programa de intervenção, traduzido num protocolo de parceria a celebrar entre todas as entidades envolvidas na sua execução." Destaca-se o valor atribuído à participação dos actores em todo o processo pondo em relevo as parcerias protocoladas para a sua execução. Fica clara a necessidade de promover a interacção entre as populações, os técnicos, os decisores e administradores públicos, através de um trabalho conjunto ao longo de seis meses, que permita, estrategicamente, elaborar um diagnóstico e definir um plano de acção consensual e realista, para uma efectiva resolução dos

\footnotetext{
Adopção do conceito de "projecto de cidade" agora aplicado a uma escala mais pequena.

${ }^{8}$ Resolução do Conselho de Ministros n. ${ }^{\circ}$ 142/2005 - Iniciativa Qualificação e Reinserção Urbana de Áreas Críticas.
} 
problemas desses territórios. Será a partir desta metodologia participativa de planeamento que irão surgir novas ideias e novas soluções que permitam realizar intervenções relativamente consensuais e de acordo com a realidade, mas também fazer com que as populações e os actores se identifiquem mais com o próprio projecto, tornando-se assim verdadeiros protagonistas.

Numa sociedade de constantes mudanças e de adversidades e que por isso exigem respostas inovadoras na forma de intervir nos territórios e em especial em zonas críticas com problemas específicos e agravados, a metodologia do planeamento estratégico parece ser então a mais eficaz e eficiente, dado que "constitui, pois, uma metodologia de decisão e acção que tem demonstrado singulares virtualidades para lidar com a escassez de recursos, a selecção de projectos e investimentos $e$ a mobilização dos agentes" (Ferreira, 2005:125). No entanto, urge definir "quais são os actuais instrumentos de planificação e de gestão territorial capazes de dar resposta ágil e adequada às mudanças do contexto exterior e que considerem a diversidade de interesses (...)" (Guerra, 2000: 42).

Se um importante passo é a vontade política para o exercício de uma maior participação ao nível da gestão dos territórios, o segundo passo é a mobilização e o processo para operacionalizar essa democracia participativa, num ambiente em que ainda prevalecem mecanismos tradicionais e uma cultura cívica pouco responsável e crente dos seus direitos, ou pouco habituada a ser chamada a exercê-los. O desafio colocado, no apoio à elaboração da intervenção, foi implementar uma metodologia de planeamento estratégico que proporcionasse formas de exercício democráticas aos actores individuais e colectivos.

O movimento, seja ele centrípeto ou centrífugo, remete para a ideia de passagem, para a noção de dinâmica, para a ideia de transformação. É o tempo que marca a progressão das percepções numa posição do espaço (Pearson, 2004 [1892]) e da ausência de imagens comuns para a presença de percepções divergentes e daqui para perspectivação de possibilidades de futuro alternativas. A plasticidade metodológica desenvolvida, que se sedimenta epistemologicamente numa sociologia das ausências e das emergências (Santos, 2003, 2006), permitindo ir para lá das evidências da realidade vivida e desocultando processos e dinâ- micas generativas que a constituem (Danermark et $a l ., 2002)$, significa a exploração de um tempo que se abre à multiplicidade, um tempo profano e policromático (Hall, 1989). O tempo percepcionado é puramente a ordem de sucessão das nossas impressões sensoriais e não envolve qualquer ideia de tempo absoluto (Pearson, 2004 [1892]), corresponde a uma temporalidade que pretende desvendar, criar, imaginar o real, fazendo corresponder o tempo a esse exercício. Amplia o campo das experiências, dilatando o presente. Com esta ampliação aumenta também as possibilidades de experimentação social no futuro. A dilatação do presente dá-se pela expansão do que é considerado contemporâneo, pelo achamento do tempo presente de modo a que todas as experiências e práticas que ocorrem simultaneamente possam ser consideradas contemporâneas, ainda que sejam diferentes ou divergentes (Santos, 2003).

Contrair o futuro significa torná-lo escasso, passando a ser um objecto cuidado. Enquanto a dilatação presente é conseguida através de uma sociologia das ausências, a contracção do futuro é conseguida por meio de uma sociologia das emergências. Esta sociologia consiste em substituir o vazio do futuro segundo o tempo linear por um futuro de possibilidades plurais que se vão construindo através de actividades de cuidado (Santos, 2003, 2006). O elemento subjectivo da sociologia das ausências é a consciência cosmopolita e o inconformismo ante o desperdício da experiência. O elemento subjectivo da sociologia das emergências é a consciência antecipatória e o incoformismo ante uma carência cuja satisfação está no horizonte de possibilidades. A sociologia das ausências move-se no campo das experiências sociais; a sociologia das emergências move-se no campo das expectativas sociais. Ao dilatarem o presente e ao contraírem o futuro, a sociologia das ausências e a sociologia das emergências, contribuem para desacelerar o presente, dando-lhe um conteúdo mais denso e substantivo do que o mero instante fugaz entre o passado e o futuro (Santos, 2003).

Espaço, tempo e movimento conferem o cenário em que se desenvolve a construção de conhecimento sobre o Vale da Amoreira e o planeamento participativo de uma futura intervenção. Operatoriamente, a sociologia em duplo-hélice de que temos vindo a falar traduz-se na activação de métodos e técnicas específicas, concebidas e 
activadas na tentativa de responder à seguinte questão "Como combinar a necessidade de um maior pragmatismo, eficiência e flexibilidade nos processos de reflexão e decisão, com a igual necessidade de uma conduta mais estratégica e integrada, com a preocupação num maior pluralismo e em valores de auscultação, e também com as crescentes necessidades de maior justiça, equidade, acção social e distributiva, nestes tempos de crescente polarização social?" (Seixas, 2000:61). Como se operacionaliza então um método de trabalho com esta ambição e como se produzem resultados perante a heterogeneidade social e cultural dos diferentes actores no terreno ${ }^{9}$ ?

O projecto desenvolvido no Vale da Amoreira tratou-se de um trabalho de laboratório, no sentido da experimentação de diferentes métodos e técnicas que promovessem resultados filhos de uma verdadeira participação cidadã. De facto, “(...) o planeamento estratégico, como qualquer ciência ou metodologia, não dispensa bases e referências teórico-conceptuais, [mas] ele é, por excelência, uma metodologia de acção, processual e adaptativa, pelo que a experimentação é, ainda, o melhor caminho para o sucesso" (Ferreira, 2005:126).

\section{O processo de trabalho}

No trabalho com os parceiros locais, o nosso esforço foi de facilitação e de mediação, no sentido da compatibilização dos diferentes interesses em jogo de forma a minimizar os conflitos dentro do grupo, e de sermos capazes de circunscrever os problemas e procurar as soluções em conjunto (sem os ocultar ou negar). Foi um trabalho de mediação entre os diferentes grupos em presença, de regulação dos conflitos latentes e muitas vezes camuflados. Esta experiência, foi de aprendizagem para nós e para as associações locais, possibilitando a emergência de uma nova capacidade de actuação na realidade do Vale da Amoreira, bem como da introdução de instrumentos de uma nova cultura de planeamento: uma cultura participativa, democrática e em parceria com aplicabilidade, quer em processos de desenvolvimento interno das organizações, quer no desenvolvimento de intervenções específicas ao nível comunitário ${ }^{10}$.

$\mathrm{O}$ trabalho participativo implica a criação de um quadro relacional pautado quer pela igualdade entre os diferentes intervenientes quer pela transparência da informação produzida. Neste sentido, a primeira fase de trabalho, coincidindo com os momentos mais intensos de uma estratégia metodológica de desocultação, foi marcada por momentos abertos de produção de informação, destacando-se: as sessões plenárias (workshop) para a identificação de problemas e obstáculos, bem como para a definição de objectivos, potencialidades e meios de acção. Foi ainda realizado o levantamento de toda a informação já produzida acerca da freguesia do Vale da Amoreira (diagnósticos, planos de actividades e projectos dos parceiros locais, etc.) e organizadas incursões no terreno de cariz etnográfico (que se prolongaram durante quase todo o período de trabalho), sentindo o Vale da Amoreira para lá do quadro das sessões de trabalho conjunto, percebendo as suas dinâmicas específicas e descobrindo novos e importantes actores locais.

O trabalho com os jovens enquanto parceiros informais, resulta desse prolongamento etnográfico do processo de planeamento permitindo a recolha de informação complementar e a construção de novos instrumentos de planeamento (como os mapas mentais do Vale da Amoreira) ficando plasmadas as centralidades e os protagonistas na identificação da diversidade e das potencialidades artísticas juvenis. Foi ainda a construção conjunta

\footnotetext{
9 É importante referir que os nossos interlocutores locais (Grupo de Parceiros Locais) era formado por vários actores colectivos, por um lado os actores institucionais e representantes dos Ministérios, desde a Cultura à Administração Interna, ao Ministério do Ambiente e do Ordenamento do Território (representado pelo INH), como ainda a Junta de Freguesia e a Câmara Municipal, por outro, os actores locais, quer da saúde (centro de saúde local) e da educação (agrupamento vertical das escolas locais), como as associações de carácter social, cultural, desportivo e religioso, que trabalham especificamente para a população do Vale da Amoreira. As associações locais devem ser entendidas como os "parceiros intermediários" aqueles que se encontram entre a comunidade e os indivíduos, com interesses, acções e funções restritas, e que por isso têm também a responsabilidade de irem informando, partilhando, recolhendo opiniões e mesmo estimulando a responsabilidade de cada cidadão para um projecto global e comunitário em construção.

${ }^{10}$ É importante reconhecer que em muitos destes territórios existem actores locais que nem sempre têm capacidade para uma visão de conjunto que um projecto como este exige. Estes tendem muitas vezes a focalizar-se nos seus problemas, nos das suas associações e nos da sua população-alvo. Se isto não for ultrapassado, poderá originar problemas graves entre os vários actores e interferir nas propostas para as soluções dos problemas. Cabe à equipa técnica ajudar a entender a importância de uma visão de conjunto, a desconstruir os problemas, a interpretar a causa dos mesmos e ajudar a identificar pistas para a sua resolução que ultrapassem os âmbitos de actuação e os interesses de cada parceiro.
} 
de uma ficha de identificação das competências dos jovens do Vale da Amoreira que ajudou a entender este universo juvenil.

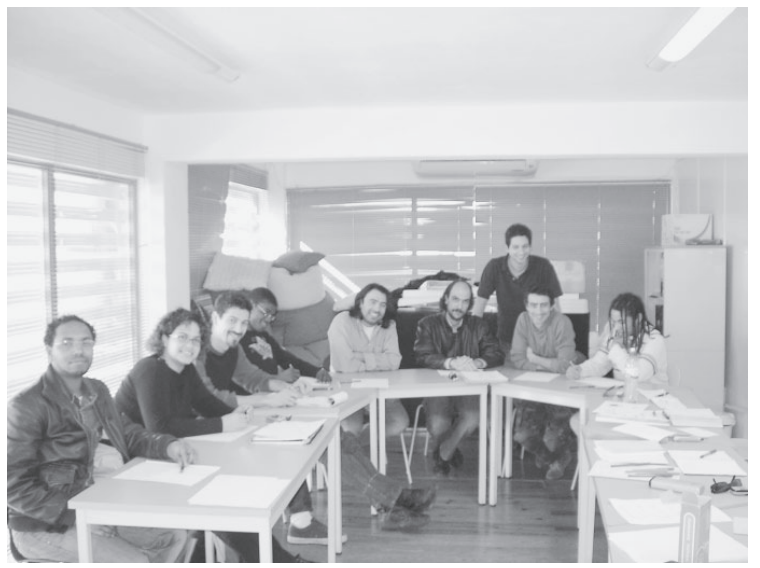

Workshop com os jovens - parceiros informais

A necessidade de se elaborar um plano de acção marca a entrada numa segunda fase. Se considerarmos a fase anterior como um período de aprendizagem e de adaptação, esta segunda fase caracteriza-se pelo crescimento e maturação nas formas de trabalho. De forma genérica podemos dizer que se dá, por parte dos actores locais, a passagem de uma postura de interlocutores-reactores às formas de trabalho propostas, para activos dinamizadores das sessões de trabalho colectivo. Emerge uma capacidade de auto-gestão do processo participativo, o que não deixa de transportar consigo conflitos e uma enorme necessidade de vigilância da nossa parte enquanto facilitadores de um olhar problematizador e crítico.

Esta nova fase é inaugurada com um workshop para a produção de ideias para uma intervenção no Vale da Amoreira, um primeiro exercício no sentido da definição de projectos e acções. Em seguida, tendo sido estabilizado o universo de ideias para intervenção através do exercício anterior, tornou-se evidente para todos a necessidade das ideias serem trabalhadas em diferentes sentidos, colmatando algumas deficiências: (i) eliminar sobreposições e repetições; (ii) estabelecer projectos estruturantes que dessem coerência às acções e ideias propostas, evitando uma intervenção atomizada, desadequada e desarticulada; (iii) investir em formas inovadoras de intervenção; (iv) manutenção de coerência relativamente aos eixos de intervenção e objectivos estratégicos já definidos.
Neste sentido, foram organizadas sessões temáticas (focus group) para a construção de projectos estruturantes. Os parceiros locais assumiram a responsabilidade pelo decorrer destas sessões, organizando as formas de trabalho, tendo sempre em consideração os objectivos e resultados a que deveriam chegar no fim de cada sessão: (i) o debate entre os parceiros sobre a forma de intervir e o papel de cada um nessa intervenção; (ii) a eliminação de sobreposições nas propostas de intervenção; (iii) a consolidação da ideia de uma intervenção integrada e baseada em parcerias; (iv) a definição genérica de projectos estruturantes e as suas acções fundamentais.

Depois de genericamente definidos os projectos estruturantes, foi organizada uma sessão conjunta para a consolidação desses projectos, tendo como resultado: (i) a identificação de transvazes entre diferentes projectos e diferentes eixos de intervenção, o que permitiu a emergência de projectos mais estruturantes e indutores de mudança; (ii) o estabelecimento de coerência interna à Operação Vale da Amoreira, podendo falar-se na construção de um programa de intervenção com quatro grandes projectos integrados.

Era chegado o momento da definição do plano de acção com a calendarização de todas as actividades previstas e a identificação dos responsáveis pela sua execução. Esta tarefa exigiu um esforço negocial entre os parceiros envolvidos, nomeadamente no que diz respeito à percepção que estes têm das suas capacidades de concretização e das reais possibilidades de articulação entre as suas diferentes potencialidades e capitais de experiência. Apesar dos conflitos que emergiram entre diferentes parceiros e que têm origem numa cultura de trabalho e de actuação no terreno que se caracteriza pela fragmentação e pela concorrência na intervenção social, foi estruturado o plano de acção e identificados os parceiros locais que serão os seus promotores.

Finalmente, entrámos na fase de elaboração do modelo de gestão, mais uma vez se impôs a criatividade na concepção de numa estrutura realista para a operacionalização, coordenação e execução do projecto construído. Este último momento implicou a definição de regras, procedimentos, modos de funcionamento e de responsabilidades efectivas na coordenação da 
futura operação de intervenção no Vale da Amoreira.

\section{Quadros relacionais de pesquisa e planeamento}

Temos vindo a perceber que na relação entre o cognitivo e o instrumental, entre o conhecer e o actuar na realidade, a sociologia contribui enquanto ciência, enquanto produtora de conhecimento. Percebemos também que no centro dessa relação entre a produção de conhecimento e o planeamento da acção intervêm actores diferentes: o sociólogo, o Estado enquanto promotor das futuras políticas, sujeitos-objectos do trabalho do sociólogo e das intervenções públicas que se seguirão.

No fundo, o que estivemos até aqui a apresentar foi o traçar de um quadro relacional. Um quadro onde se estabelecem relações sociais e no qual o sociólogo não pode reivindicar uma posição de exterioridade. Tal como no contexto de outras pesquisas em sociologia, na formulação de políticas públicas estabelece-se uma relação social de pesquisa que é fortemente marcada pela negociação permanente entre estes actores (Moscovici e Willem, 1991), uma negociação fundamental e básica para a construção do conhecimento. Porque esta é uma negociação entre formas de conhecimento, discursos, representações e estratégias de significação do mundo e da experiência social distintas (Danermark et al., 2002; Nunes, 2001; Santos, 2000, 2003, 2006; Silva, 2006).

Esta dimensão relacional, tensional e negocial tende a ser esquecida, apagada ou desvalorizada quando se pensam os processos de planeamento, mesmo naqueles com a chancela do termo participativo. Isto acontece em grande medida porque se conjugam dois factores que funcionam como branqueadores dos processos sociais de pesquisa. Por um lado, o sociólogo gosta do acabado e por isso tende a apagar o percurso, tendência ainda mais evidente no trabalho de planeamento de políticas públicas, dadas as exigências de partida colocadas pelo promotor das futuras políticas. Por outro lado, o Estado (promotor das políticas) está interessado em resultados, em dados que permitam a legitimação de políticas futuras; não quer saber das dúvidas metodológicas ou epistemológicas dos investigadores. Assim, nestes contextos de trabalho sociológico, o sociólogo faz desaparecer os vestígios das pinceladas, os toques e os retoques, as definições e as redefinições (Bourdieu, 2001:19). As angústias, as dúvidas, as incertezas são ocultadas, tornando o processo de pesquisa em algo miraculosamente perfeito. Mas, são nessas dúvidas omitidas que se escondem os pontos fundamentais para a reflexão acerca de projectos desta natureza, porque, o perigo está quando as dúvidas científicas dão lugar a certezas técnicas.

Esta omissão reflexiva torna-se mais clara se recorrermos à semântica: planear significa fazer o plano, projectar, tencionar. Plano significa raso, liso, chão, que não tem desigualdades ou diferenças de nível, fácil, acessível, claro. Fazer o plano é tornar as realidades lisas, planas, sem desigualdades ou curvas de nível, significando apagar o percurso, esquecer as dúvidas, as incertezas, as tensões e as negociações específicas das relações sociais que se estabelecem num processo participativo. Resultaria em ter apenas o plano de acção como única existência, como produto acabado, que se reifica. Neste sentido, o processo auto-reflexivo surge como forma de recuperar a experiência que é desperdiçada por uma lógica estritamente produtivista que visa um resultado final - um plano para a intervenção acabado.

A auto-reflexividade assume-se, assim, como uma forma de evitar o desperdício da experiência que coloca no centro a dimensão relacional estabelecida com os diferentes actores envolvidos nesse processo de construção participada de um instrumento político. Esta recuperação da experiência, traduz-se na reafirmação da articulação entre a prática de uma sociologia sensível e um planeamento participativo. A reflexividade é de importância central para o desenvolvimento da pesquisa social, onde a ligação entre pesquisador e ambiente de pesquisa é próxima, onde a natureza dos objectos de estudo - sujeitos conscientes - influencia o curso dos acontecimentos e onde se estabelecem relações sociais (Davies, 2005).

As relações com os informantes no campo, que formam as bases da subsequente teorização e conclusões, são expressas através da interacção social na qual participamos; assim, nós próprios ajudamos a construir as observações que se transformam nos nossos dados. Fazemos parte de um processo social em que os intervenientes (os pesquisadores e os pesquisados, informantes) estão 
determinados numa construção do mundo. Mas, este processo é melhor percebido enquanto um encontro no qual o conhecimento é constituído de forma a reflectir e manter várias relações de poder.

Em primeiro lugar, aqueles que o sociólogo pretende objectivar são concorrentes pelo monopólio da objectivação objectiva. O sociólogo está mais ou menos afastado dos actores e das coisas em jogo por ele observadas, mais ou menos envolvido em rivalidades com eles, mais ou menos tentado a entrar no jogo do metadiscurso com aparências de o objectivar. É a relação entre as posições de observador e observado ocupam nos respectivos campos, objectivamente hierarquizados, que comanda a percepção do observador, sobretudo impondo-lhe cegueiras reveladoras dos seus interesses obscuros, ou não assumidos (Bourdieu, 2001).

Em segundo lugar, os actores locais colectivos formam activamente e pela sua prática quotidiana a realidade que discursivamente reconfiguram em conjunto. Ou seja, num processo de planeamento desta natureza, assumem um duplo papel de construtores da realidade: por um lado, constroem praticamente a realidade, todos os dias e pelas suas acções/intervenções concretas no Vale da Amoreira e junto dos seus habitantes; por outro lado, e ao mesmo tempo, no processo de planeamento participado, porque considerados interlocutores privilegiados, voltam a (re)construir essa realidade em que participam. Neste processo reconstroem a realidade e a si próprios e o seu lugar no espaço do Vale da Amoreira. Este duplo estatuto de construção da realidade confere um enorme poder a estes actores colectivos.

Se pensarmos que os interlocutores são tanto escolhidos por nós como eles nos escolhem a nós (Davies, 2005), percebemos que eles vêem na participação num projecto desta natureza uma forma de concretização dos seus objectivos institucionais ou de afirmação no espaço político do Vale da Amoreira em que se movimentam diferentes actores colectivos privados (associações e ONG's) e públicos (representantes de Ministérios ou dos seus serviços descentralizados e poder autárquico).

Os actores locais têm a capacidade de perceber claramente o que está em causa neste processo; desde a primeira hora percebem de forma prática que nos nossos encontros se joga a construção do futuro do Vale da Amoreira e se definem os lugares de cada um deles nesse futuro próximo. O quadro das relações de poder futuras está a ser desenhado no presente, eles participam desse desenho, logo, as lutas pelas posições sociais de dominação no interior do campo dão-se no presente, na contemporaneidade do processo de planeamento. Esta consciência prática levanta questões operacionais que exigem uma constante negociação e transparência na comunicação (transparência nos métodos de produção da informação, estabelecendo um sistema de produção de informação e de comunicação baseado na igualdade entre pares), para que se estabeleça confiança básica entre todos os actores e entre eles e nós, à partida um corpo estranho ao território.

Finalmente, em terceiro lugar, devemos perceber que o consentimento não é um momento único, é um processo que necessita de renegociação ao longo do tempo da pesquisa (Moscovici e Willem, 1991), possibilitando a participação dos diferentes actores locais, sabendo gerir as oscilações entre a motivação e a saturação num processo de pesquisa longo e com uma relação social não desprovida de tensões e conflitos. A pesquisa social envolve uma multiplicidade de relações entre uma grande diversidade de indivíduos: entre o pesquisador e uma série de porteiros (aqueles que controlam, simbolicamente, o acesso aos locais e agentes da pesquisa); entre pesquisador e pesquisados. Os porteiros (gatekeepers) podem ter ou exercer autoridade sobre outros mas o seu consentimento não traduz necessariamente a vontade de participação desses outros sobre os quais exerce autoridade.

$\mathrm{O}$ pesquisador deve ter o consentimento dos seus interlocutores directos e de uma forma directa (Davies, 2005). Esta situação torna-se paradoxal no Vale da Amoreira, na medida em que temos como interlocutores privilegiados actores locais colectivos, representantes de importantes sectores da população local mas com poderes muito limitados no que respeita à mobilização da população para a participação num processo desta natureza. Os parceiros locais (actores locais colectivos) funcionavam, muitas vezes, como porteiros para o vazio, as portas que guardam e representam um acesso enfraquecido à realidade. Porque estes são porteiros institucionais, ser-se guardado por eles significa que se está de alguma forma institucionalizado, se pertence ou se aceita 
uma ordem instucional e política local, que passa pelas associações locais ou de acção local, pela Junta de Freguesia ou Câmara Municipal (poder autárquico), ou ainda pela autoridade do Estado representada por diversos Ministérios e seus serviços descentralizados.

Percebemos a existência de porteiros simbólicos cujo poder é bem mais valioso e que guardam o acesso a dimensões e dinâmicas locais que estão na sombra de todos os dias. O problema era como conseguir chegar até eles, como estabelecer o primeiro contacto: quem nos poderia apresentar a esses novos porteiros? Assim, a adopção de uma estratégia do tipo snowball era inevitável para aceder a estes outros porteiros, a outros informantes e a outras dimensões da realidade. Para isso, activou-se a capacidade simbólica dos nossos pareceiros locais institucionais (o seu poder enquanto porteiros), transformando-os em interlocutores de partida pretendendo chegar a outros informantes priveligiados: informantes de segunda e terceira ordem, informantes cada vez mais grounded e menos afectos e dependentes das redes institucionais.

Constituímos, desta forma, um quadro relacional de pesquisa e de construção de possibilidades de futuro denso quer do ponto dos actores envolvidos, quer no que diz respeito aos cenários em que estes actores se cruzam e produzem esses novos futuros possíveis para o Vale da Amoreira metodologicamente fundamentais e epistemologicamente fundamentados.

\section{Considerações finais}

Em jeito de conclusão podemos dizer que, no contexto da prática de uma sociologia de duplo-hélice está implícito o afastamento de posições herdeiras do positivismo que pretendem prender a ciência a uma hipotética superioridade e neutra- lidade, vincando a passagem de uma postura normativista da modernidade para a interpretação e tradução da pós-modernidade, recentrando o exercício da comunicação e da tradução entre diferentes quadros culturais e simbólicos e a interpretação dos textos, dos discursos, das imagens e dos movimentos, que informam a nossa contemporaneidade (Silva, 2006, Santos, 2000, 2003, 2006).

Quanto à questão inicial sobre qual o contributo do sociólogo e da sociologia no contexto de produção de políticas públicas, ou a interrogação quanto às formas de articulação entre as dimensões cognitiva e instrumental (entre o conhecer e o actuar), percebemos que a prática de uma sociologia em duplo-hélice tem dois efeitos fundamentais: por um lado, lança as bases para a construção de conhecimento teórico em que a sociologia se mostra consciente da incompletude e da transitoriedade do saber produzido (Danermark et al., 2002; Silva, 2006; Santos, 2000, 2003, 2006) e desta forma, o que se procura é a montagem de dispositivos de pesquisa como uma estratégia de aprendizagem para o sociólogo e para a disciplina através das relações sociais estabelecidas com os protagonistas sociais que estudam. Por outro lado, esta prática sociológica é possibilitadora da acção sobre o mundo social, uma acção sedimentada não apenas nas evidências da realidade, mas nos seus mais profundos mecanismos e processos de constituição (a sua dimensão oculta).

A sociologia em duplo-hélice na sua postura metodológica e na sua plasticidade metodológica afirma-se como um espaço onde se articula conhecimento sociológico e acção política e onde se conjuga sociologia sensível e objectivos do planeamento estratégico, permitindo a constituição de um campo de confluência e tradução entre saberes de naturezas diferentes na construção de conhecimento e acção social como construção de novas possibilidades de futuro. 


\section{Referências Bibliográficas}

AFONSO, João, COELHO, Bernardo S., AMARO, André, MATOS, José, GARCIA, Ana (2006), Iniciativa Bairros Críticos. Operação de Qualificação e Reinserção Social e Urbana do Vale da Amoreira - Moita, Lisboa: INH e CET/ /ISCTE.

BONETTI, M., SÉCHET, P. (2002), “Démarches de Développement: la participation des habitants", in Cidades, Comunidades e Territórios, n. ${ }^{\circ} 4$, Centro de Estudos Territoriais/ISCTE: Lisboa.

BORJA, J., CASTELLS, M. (1997), Local \& Global: Management of Cities in Information Age, London: Hearthscan Publications.

BOURDIEU, Pierre (2001), O Poder Simbólico, Lisboa: Difel.

CASTRO, José L., GONÇALVES, Alda T. (2002) “A rede social e o desenvolvimento local: parcerias sociais e planeamento participado", in Cidades, Comunidades e Territórios, n. ${ }^{\circ} 4$, Centro de Estudos Territoriais/ISCTE: Lisboa.

DANERMARK, Berth, EKSTROM, Mats, JAKOBSEN, Liselotte, KARLSON, Jan (2002), Explaining Society. Critical Realism in Social Sciences, London: Routledge.

DAVIES, Charlotte Aull (2005), Reflexive Ethnography: a guide to researching selves and others, New York: Routledge.

FERMISSON, João (1998), "Problemas de promoção do desenvolvimento em Portugal: rumo a estratégias territorializadas de base local e regional", in Territórios Alternativos. Actas do Colóquio: Territórios Alternativos, Ciência e Desenvolvimento, Grândola: Instituto de Estudos Superiores do Litoral Alentejano.

FERREIRA, António Fonseca (2005), Gestão Estratégica de Cidades e Regiões, Fundação Calouste Gulbenkian, Lisboa.

GLASER, Barney G., STRAUSS, Anselm L. (1967), The Discovery of Grounded Theory. Strategies for Qualitative Research, New York: Aldine Publishing Company.

GUERRA, Isabel (2000), Fundamentos e Processos de Uma Sociologia de Acção. O Planeamento em Ciências Sociais, Principia: Cascais.
GUERRA, Isabel (2001), “Intervenções face à exclusão social urbana: uma luta inglória?", in Cidades, Comunidades e Territórios, n. ${ }^{\circ}$ 2, Centro de Estudos Territoriais/ISCTE: Lisboa.

HALL, Edward T. (1989), The Dance of Life: the other dimension of time, New York: Anchor Books.

MAFFESOLI, Michel (1998), Elogio da Razão Sensível, Petrópolis: Editora Vozes.

MERLEAU-PONTY, Maurice (2002), Phenomenology of Perception, London: Routledge.

MOSCOVICI, Serge, DOISE, Willem (1991), Dissensões e Consenso. Uma Teoria Geral das Decisões Colectivas, Lisboa: Livros Horizonte.

NUNES, João Arriscado (2001), "Teoria crítica, cultura e ciência", in SANTOS, Boaventura de Sousa (Org.) (2001), Globalização: Fatalidade ou Utopia?, Porto: Afrontamento.

PAIS, José Machado (2002), Sociologia da Vida Quotidiana, Lisboa, ICS.

PEARSON, Karl (2004 [1892]), The Grammar of Science, New York: Dover Publications.

SANTOS, Boaventura de Sousa (2000), A Crítica da Razão Indolente: Contra o desperdício da experiência, Porto: Afrontamento.

SANTOS, Boaventura de Sousa (2003), "Para uma sociologia das ausências e uma sociologia das emergências", in SANTOS, Boaventura de Sousa (Org.) (2003), Conhecimento Prudente para uma Vida Decente, Porto: Afrontamento.

SANTOS, Boaventura de Sousa (2006), A Gramática do Tempo: Para uma nova cultura política, Porto: Afrontamento.

SEIXAS, João (2000), "A cidade não governada", in Cidades, Comunidades e Território, n. ${ }^{\circ} 4$, Centro de Estudos Territoriais/ /ISCTE, Lisboa.

Silva, Augusto Santos (2006), A Sociologia e o Debate Público. Estudos sobre a Relação entre Conhecer e Agir, Porto: Afrontamento. 